\title{
Definitive Estimate of Rate of Hemoglobin Switching: Measurement of Percent Hemoglobin $F$ in Neonatal Reticulocytes
}

\author{
H. M. PHILLIPS, B. M. HOLLAND, J. G. JONES, A. L. ABDEL-MOIZ, T. L. TURNER, AND \\ C. A. J. WARDROP \\ Department of Haematology, University of Wales College of Medicine, Cardiff, Wales [H.M.P., C.A.J.W.]; \\ Department of Child Health, University of Glasgow, Queen Mothers Hospital, Glasgow, Scotland [B.M.H., \\ A.L.A-M., T.L.T.J; and Department of Biochemistry, University College, Cardiff, Wales [J.G.J.]
}

\begin{abstract}
The transition from fetal to adult erythropoiesis starts at 32-36 wk postconception. The rate of this switchover has been controversial. Studies of globin chain synthesis by reticulocytes in vitro have indicated gradual switching with a time for $\mathbf{5 0 \%}$ reduction in fetal $\mathbf{H b}$ synthesis ("half-time") of more than 6 wk. This may not accurately reflect fetal/adult $\mathrm{Hb}$ synthetic balance in vivo. By contrast, histochemical studies and also indirect mathematical analysis of postnatal changes in circulating fetal $\mathrm{Hb}$ and adult $\mathrm{Hb}$ may imply abrupt patterns of switching with half-times of less than $1 \mathrm{wk}$. We have resolved this discrepancy by direct measurement of the changing proportions of fetal and adult $\mathrm{Hb}$ in reticulocytes prepared by flourescence activated cell sorting from 10 full-term cord and 45 preterm postnatal blood samples. This method overcomes problems both of extrapolation from in vitro measurements and of mathematical analysis. We find a gradual transition from fetal $\mathbf{H b}$ to adult $\mathrm{Hb}$ synthesis. The half-time is approximately 16-18 wk. Values of fetal $\mathrm{Hb}$ in reticulocytes were on average higher than predicted from in vitro synthesis studies. We find considerable individual variation. Infants differ in their switching behaviour, many showing prolonged dependence on fetal $\mathrm{Hb}$. (Pediatr Res 23: 595-597, 1988)
\end{abstract}

Abbreviations

$\mathrm{HbF}$, fetal $\mathbf{H b}$

$\mathrm{HbA}$, adult $\mathrm{Hb}$

FACS, fluorescence activated cell sorter

$\mathrm{HbF}$, optimal for oxygen transport in utero, is progressively replaced by $\mathrm{HbA}$ from about 32-36 wk of gestation (1). This maturational phenomenon is clinically important and shows marked individual variation. Prolonged postnatal dependence on $\mathrm{HbF}$ impairs oxygen transport and has been associated with clinically significant anaemia and with the sudden infant death syndrome $(2,3)$. Despite its biological importance the time course of switching has remained controversial (1). There are theoretical reservations about the validity of methods previously used to study $\mathrm{Hb}$ switching. These depend respectively on in vitro globin chain synthesis (4), on histochemical studies based

Received September 9, 1987; accepted February 2, 1988. Correspondence Heather M. Phillips, Department of Haematology, University of Wales College of Medicine, Heath Park, Cardiff CF4 4XN, Wales.

Support by Welsh Scheme for the Development of Health and Social Research The Jane Hodge Foundation. on acid elution (5), and on indirect mathematical analysis of circulating fetal and adult $\mathrm{Hb}(6,7)$.

Studies of $\mathrm{Hb}$ actively synthesized by reticulocytes in vitro imply a gradual decline of $\mathrm{HbF}$ synthesis after a sigmoid curve, the "steep" part starting at about $32 \mathrm{wk}$ gestation and proceding such that the "half-time" for $50 \%$ reduction in $\mathrm{HbF}$ synthesis is $>6 \mathrm{wk}$. There is a corresponding increase in $\mathrm{HbA}$ production. This technique, which assesses $\mathrm{HbF} / \mathrm{A}$ synthetic balance at the end of erythroid maturation in vitro, may not accurately reflect events in vivo.

Studies using the acid elution method of Betke and Kleihauer for detecting $\mathrm{HbF}$ in erythrocytes point to the sudden appearance of a distinct subpopulation of cells containing predominantly $\mathrm{HbA}$ at about the time of resumption of erythropoiesis after the postnatal erythropoietic shut-down. This suggests a fairly rapid process followed by the appearance of a new population of erythroid cells containing $\mathrm{HbA}(1,5)$.

A similiar pattern can be inferred from mathematical analyses of the changing proportion of $\mathrm{HbF}$ and $\mathrm{HbA}$ in the circulation of individual infants studied postnatally. Mathematical analyses could be taken to imply that, on resumption of erythropoiesis after the postnatal shut-down, HbF synthesis has completely ceased $(6,7)$. The histo-chemical and mathematical findings could be reconciled with the in vitro observations by assuming that the switchover occurs gradually during a period of relatively inactive erythropoiesis and that, when erythropoiesis resumes, any residual $\mathrm{HbF}$ synthesis is insufficient to be detected by these techniques. However, this hypothesis has not been proven and the controversy between rapid and slower rates of switching has not yet been satisfactorily resolved.

The discrepancies relating to the time course of the switching process prompted us to develop a direct means of assessing $\mathrm{HbF}$ to $\mathrm{HbA}$ switching patterns in infants by measurement of the $\% \mathrm{HbF}$ in reticulocytes harvested from the peripheral blood at different postconceptual stages. We consider that the $\% \mathrm{HbF}$ of reticulocytes accurately reflects the balance of $\mathrm{HbF} / \mathrm{A}$ synthesis in the bone marrow in the $2-3$ days immediately preceding sampling. This direct approach overcomes the shortcomings associated with the indirect nature of the previous studies.

\section{PATIENTS}

Thirty preterm infants of gestation at birth 26-33 wk (mean $29.5 \pm 1.74 \mathrm{wk}$ SD) were studied on a total of 45 occasions. Twelve blood samples were from infants of postnatal age $<1 \mathrm{wk}$ (mean 2 days \pm 2.2 days SD, range: birth -6 days) and 33 samples were from infants of postnatal age $>1 \mathrm{wk}$ (mean $=7.2 \pm 3.5 \mathrm{wk}$, range 2.9-21.4 wk). The severity of complications of preterm delivery differed between the individual infants. Seventeen babies 
needed red cell transfusion for sampling or spontaneous blood losses and/or the refractory early anemia of prematurity at some time during their clinical course. Six babies had intrauterine growth retardation (indicated by the asterisk in Fig. 2) but none had evidence of hemolytic disease, hemoglobinopathies or maternal diabetes. Ten umbilical cord blood samples from full-term healthy newborns of gestation at birth $37-43 \mathrm{wk}$, (mean $=40.5$ \pm 2.2 wk SD) were also studied for comparison. Reticulocyte counts at sampling ranged from 3 to $14 \%$.

\section{METHODS}

Preparation of concentrated reticulocytes. We used an adaptation of the method described by Sage et al. (8) that identifies and sorts out reticulocytes using the FACS on the basis of their preferential staining with the fluorescent nucleic acid dye, thioflavin $T$. Thioflavin $T$ binds to intracellular RNA, and reticulocytes, by virtue of their higher RNA content, fluoresce more brightly than mature erythrocytes when intercepted by laser light of suitable wavelength. This method is especially applicable to small volumes of blood $(5-25 \mu 1)$. A total of $5 \mu 10.01 \%$ thioflavin $\mathrm{T}$ in isotonic phosphate-buffered saline was added to $5 \mu$ l EDTA anticoagulated whole blood and incubated for $7 \mathrm{~min}$ at room temperature. The cell suspension was then diluted with 5-10 ml buffered saline and reticulocytes sorted out using either the FACS III or FACS 440 (Becton Dickinson FACS Systems, Sunnyvale, CA). The argon-ion laser (Spectra-Physics Inc., Mountain View, CA) provided $100 \mathrm{~mW}$ of excitation at $457 \mathrm{~nm}$. The fluorescence of the red blood cells was detected by an EMI 9924A photomultiplier tube after passing through 535-nm band pass filter. The resulting signal was amplified linearly. Fluorescence characteristics of the red cell population were expressed as fluorescence histograms (Fig. 1). Most of the cells possessed only low levels of fluorescence, (these are mature erythrocytes) whereas a smaller number of cells showed higher levels of fluorescence. A threshold was set at the discontinuity in the fluorescence histogram and cells above this predetermined threshold level were sorted out. These cells were found to be a highly enriched population of reticulocytes. Approximately $3 \times 10^{5}$ reticulocytes were sorted into a collection pot containing heat-inactivated fetal calf serum and then pelleted by centrifugation. The time required to obtain this number of cells depended on the percentage of reticulocytes in the original sample. The cell sample was resuspended in saline and divided to provide two aliquots each of about $1.5 \times 10^{5}$ cells. These samples were centrifuged once again and used as follows.

Verification of reticulocyte enrichment. A total of $1.5 \times 10^{5}$ cells was stained with new methylene blue to allow verification

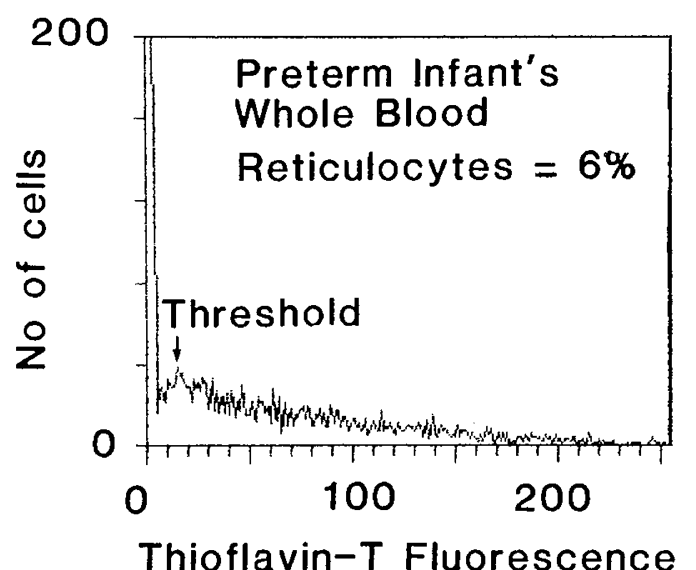

Fig. 1. Frequency histogram of thioflavin T-stained whole blood cell suspension. Number of cells is plotted against relative Thioflavin $T$ fluorescence. The threshold is indicated, above which the majority of cells are reticulocytes. or reticulocyte enrichment. A total of $100 \mu \mathrm{l}$ fetal calf serum and $50 \mu 11 \%$ new methylene blue was added to cells followed by incubation at $37^{\circ} \mathrm{C}$ for $15 \mathrm{~min}$ and then cytospin (Shandon Southern Cytocentifuge Inc., Sewickley, PA) at about $650 \mathrm{rpm}$ for $15 \mathrm{~min}$. Cytospin preparations were examined microscopically under oil immersion. Reticulocyte counts were obtained in 41 of 55 samples. The reticulocyte enrichment was generally good. In $95 \%$ of samples the reticulocyte count was $70 \%$ or more.

Measurement of $\% \mathrm{HbF}$ in enriched reticulocyte preparation. The $\% \mathrm{HbF}$ in $1.5 \times 10^{5}$ cells was measured using a modified alkali denaturation procedure. This was a "scaled down" version of our previously reported method (9) to allow quantitation of $\% \mathrm{HbF}$ in the very small total amounts of $\mathrm{Hb}$ present $(\mathrm{ca} .5 \mu \mathrm{g}$ $\mathrm{Hb}$ ). The cells were lysed in $250 \mu \mathrm{l}$ ammoniated water $(25 \mathrm{mmol} /$ liter) in a glass microcuvette and $5 \mu \mathrm{l} \mathrm{mol} /$ liter $\mathrm{NaOH}$ added to initiate denaturation. (Delay between lysis of celis and denaturation should be minimized to $5-10 \mathrm{~min}$ because prolonged exposure to ammoniated water may cause destabilization of the $\mathrm{Hb}$.) The denaturation reaction was followed at $415 \mathrm{~nm}$ with a Pye Unicam SP8-100 spectrophotometer over a 12-min period. We have found monitoring changes in optical density at this wavelength, an approximately 10 -fold increase in sensitivity over monitoring at $542 \mathrm{~nm}$. Calculation of the $\% \mathrm{HbF}$ by computer analysis was as described previously (9). (CV for test using $1.5 \times$ $10^{5}$ cells $=6.73 \%$.) Staining of cells with thioflavin $\mathrm{T}$ did not affect the $\mathrm{Hb}$ absorption spectrum or the measurement of $\% \mathrm{HbF}$ at $415 \mathrm{~nm}$.

\section{RESULTS}

High levels of $\% \mathrm{HbF}$ were found in the reticulocytes of preterm infants at different postnatal ages and in term newborns (Fig. 2). These findings suggest a gradual rate for the switchover from $\mathrm{HbF}$ to $\mathrm{HbA}$ synthesis (half-time 16-18 wk). In general this accords with the in vitro reticulocyte globin synthesis studies reported by Bard (4). We have computed lines of "best fit" which allow visual comparison of our data with the in vitro globin chain synthesis findings of Bard (4) (Fig. 2). Direct comparison of experimental data in age-matched infants (grouped in weekly intervals) show that our values for $\% \mathrm{HbF}$ in reticulocytes differ significantly from $\% \mathrm{HbF}$ synthesis values derived from the in vitro studies of Bard: mean difference $=8.93 \%, p=0.043$. The difference becomes greater with increasing age: $r=0.86, p<$ 0.05 . There is considerable individual variation in the extent to which the switching process has proceeded at any age. This is more marked at later stages of switching.

\section{DISCUSSION}

Analysis of $\% \mathrm{HbF}$ in reticulocytes is consistent with a smooth, gradual transition from $\mathrm{HbF}$ to $\mathrm{HbA}$ synthesis. In agreement with other workers $(10)$, preterm infants aged more than $1 \mathrm{wk}$, studied on resumption of erythropoiesis after the immediate postnatal shutdown, synthesize a large proportion of $\mathrm{HbF}$. In general, this accords with the in vitro globin chain synthetic data although our results for $\% \mathrm{HbF}$ in reticulocytes are on average statistically significantly higher than the data of Bard (4). This difference increases with increasing maturity and indicates a difference in the mean rates for $\mathrm{Hb}$ switching. There are two possible explanations for this discrepancy. First, it may reflect methodological differences between the studies. The present method estimates the proportions of $\mathrm{HbF}$ and $\mathrm{HbA}$ in the youngest red cells in the circulation. Inasmuch as reticulocytes mature to erythrocytes within 2-3 days of release from the bone marrow, this will approximate to the synthetic balance obtaining in the bone marrow immediately preceding sampling. This may not be accurately reflected by the globin chain synthetic capability of reticulocytes in vitro.

Alternatively, the differences between the findings could be explained by differences in the populations studied. Neonatal 


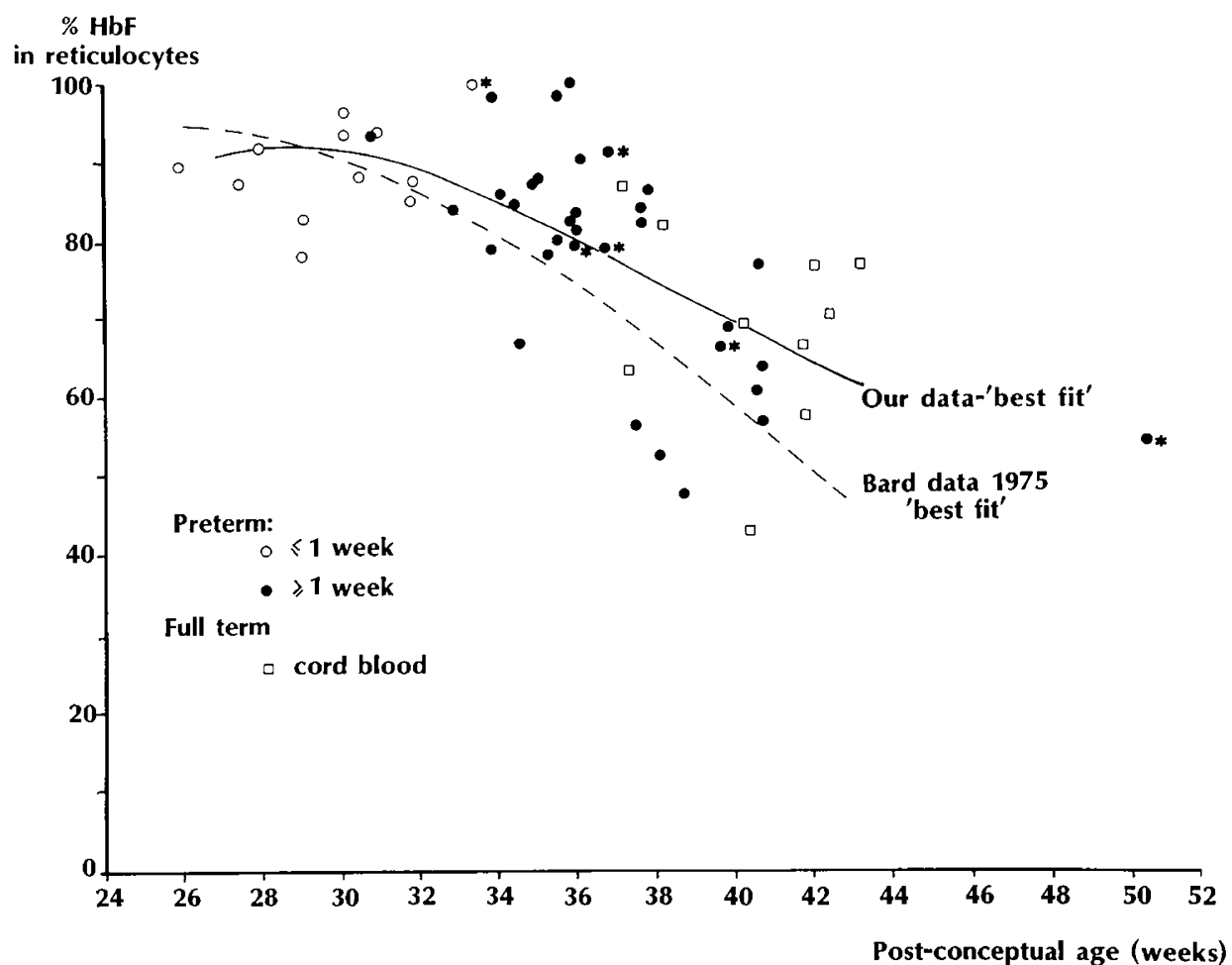

Fig. 2. Percent $\mathrm{HbF}$ in reticulocytes from preterm and newborn term infants. Babies with the intrauterine growth retardation are indicated by an asterisk.

intensive care units have a higher proportion of very preterm infants than would have obtained at the time of Bard's study in the early 1970s. These infants suffer hypoxic and other stresses and may show delayed switching behavior in association with stress erythropoiesis (11). Our results do not support the rapid rate for switching inferred from mathematical $(6,7)$ and histochemical (5) studies. Such analyses may be relatively insensitive to the detection of synthesis of small amounts of $\mathrm{Hb}$ when absolute rates of erythropoiesis are low. Also, even at higher rates of erythropoiesis, these techniques would fail to detect synthesis of $\mathrm{HbF}$ when this is masked by a faster rate of removal from the circulation. Thus, a falsely high rate of switchover might be implied.

From our data there is no evidence that preterm delivery per se affects the rate of switchover as the findings from cord blood samples from term infants fall on the same line as those in preterm postnatal samples. However, there is considerable scatter in the data, as in the reports of Bard (4) and Terrenato et al. (7), which becomes greater with increasing age and implies variation in the rates of switching between individuals. There is a precedent for this inasmuch as newborn infants with intrauterine growth retardation (12) and maternal diabetes (13-15) show delayed switching.

We believe that such studies of differing switching patterns in various clinical conditions are not only of basic scientific importance but also of clinical relevance. A recent study has associated elevated levels of $\mathrm{HbF}$ with the sudden infant death syndrome (3). This may be a causal relationship because prolonged postnatal dependence on $\mathrm{HbF}$, with its high oxygen affinity, tends to impair oxygen release from the blood to the tissues (2). We suggest that the present method is the most accurate and sensitive means of assessing the pattern of the switchover in individual babies.

Acknowledgments. The authors thank the nursing staff of the Paediatric Department, Queen Mother's Hospital and of the
Maternity Wards, University Hospital of Wales. We also thank Dr. T. G. Hoy for his help and Miss Andrea Beer, Mrs. Karen Seary and Mrs. Fiona Grant for secretarial assistance.

\section{REFERENCES}

1. Weatherhall DJ, Clegg JB 1981 Erythropoiesis. Developmental changes in haemoglobin and red-cell production. In: The Thalassaemia Syndromes, 3rd ed. Blackwell Scientific Publications, Oxford, pp 66-70

2. Wardrop CAJ, Holland BM, Veale KEA, Jones JG, Gray OP 1978 Nonphysiological anaemia of prematurity. Arch Dis Child 53:855-860

3. Giulian GG, Gilbert EF, Moss RL 1987 Elevated fetal hemoglobin levels in sudden infant death syndrome. N Engl J Med 316:1122-1126

4. Bard H 1975 The postnatal decline of hemoglobin F synthesis in normal fullterm infants. J Clin Invest 55:395-398

5. Shepard MK, Weatherall DJ, Conley CL 1962 Semiquantitative estimation of the distribution of fetal hemoglobin in red cell populations. Bull Johns Hopkins Hosp 110:293-308

6. Colombo B, Kim B, Atencio RP, Molina C, Terrenato L 1975 The pattern of fetal hemoglobin disappearance after birth. Br J Haematol 32:79-87

7. Terrenato L, Bertilaccio C, Spinelli P. Colombo B 1981 The switch from hemoglobin $\mathrm{F}$ to $\mathrm{A}$ : the time course of qualitative and quantitative variations of hemoglobins after birth. Br J Haematol 47:31-41

8. Sage BH, O'Connell JP, Mercolino TJ 1983 A rapid, vital staining procedure for flow cytometric analysis of human reticulocytes. Cytometry 4:222-227

9. Phillips HM, Holland BM, Moiz AA, Fayed S, Jones JG, Turner TL, Wardrop CAJ, Cockburn F 1986 Determination of red cell mass in assessment and management of anaemia in babies needing blood transfusion. Lancet 1:882884

10. Brown MS, Phibbs RH, Dallman PR 1985 Postnatal changes in fetal hemoglobin oxygen affinity and 2-3-disphosphoglycerate in previously transfused preterm infants. Biol Neonate 48:70-76

11. Papayannopoulou TH, Vichinsky E, Stamatoyannopoulos G 1980 Fetal Hb production during acute erythroid expansion. Br J Haematol 44:535-546

12. Bard H 1974 The effect of placental insufficiency on fetal and adult hemoglobin synthesis. Am J Obstet Gynaecol 120:67-72

13. Bard H, Prosmanne J 1985 Relative rates of fetal hemoglobin and adult hemoglobin synthesis in cord blood of infants of insulin-dependent diabetic mothers. Pediatrics 75:1143-1147

14. Perrine SP, Greene MF, Faller DV 1985 Delay in the fetal globin switch in infants of diabetic mothers. N Engl J Med 312:334-338

15. Wise JE, Sauder SE, Weiss AE 1987 Increased fetal hemoglobin production in a child with congential hyperinsulinism. J Pediatr 110:912-914 